us filter air - I would even go so far as saying we have created a new speciality within dentistry which I believe should be named as the 'Covidentologists.'

Of course there have been many examples of exemplary leadership within our profession, where clinicians have rolled up their sleeves and got on with delivering dentistry or redeployment duties during difficult circumstances for us all. Our country and profession will continue to face unprecedented challenges over the coming months.

With many predicting permanent changes for the future delivery of healthcare, one thing remains clear, the consequences of COVID-19 are far from over for dentistry. I'm sure many of the 'Covidentologists' will have a long career ahead of them guiding the many clinicians (such as myself) through the troubles and difficulties we face. I just wish I'd paid more attention during all those lectures on respiratory viruses.

W. Fitzpatrick, Cardiff, UK

https://doi.org/10.1038/s41415-020-2295-y

\section{Winter is coming}

Sir, we provide an update of the report of the enhanced Acute Dental Care (ADC) service provided by Guy's and St Thomas' NHS

Foundation Trust. ${ }^{1}$

Between the peak (22 April 2020) and 1 August 2020, the ADC service has clinically assessed a further 4,849 patients with urgent and emergency dental care needs despite the widespread establishment of Urgent Dental Care (UDC) hubs. Approximately 1,200 aerosol-generating procedures (AGPs) have been carried out, the majority being pulpal extirpations, followed by surgical extractions. The availability of re-usable FFP3 respirators and the ability to fit test clinicians has allowed an increased provision of AGPs, with fallow times for each surgery being adhered too.

The gradual resumption of elective local anaesthetic, intravenous sedation and general anaesthetic (GA) operating lists as well as face-to-face clinic appointments from 1 June 2020 has enabled the department to also assess and treat referred patients with routine dental needs. Pre-operative isolation protocols and COVID-19 testing for patients on GA lists have ensured that patient and staff safety is prioritised. This increased workload has been facilitated by the return of staff who were redeployed to other services within the Trust.

We now face a growing pressure for the directorate to resume pre-COVID-19 levels of service provision whilst maintaining urgent care. This poses a challenge considering the newfound constraints to dentistry such as fallow time, isolation of surgeries and social distancing. This dilemma is compounded by concerns over what winter may bring with regards to a second wave and further strains placed on the healthcare system. Coupled with the recent spike and mounting number of confirmed COVID19 cases nationwide, almost doubling from 7,995 in the last week of August to 12,217 in the first week of September $2020,{ }^{2}$ this challenges the practicality and sustainability of providing regular routine and elective care alongside an acute dental service.

Despite these anticipated challenges our experience of this service thus far highlights the capability of a department to effectively adapt in response to rapidly developing circumstances and can act as a framework for the provision of acute dental care in the coming months.

P. Sandhu, S. Grossman, C. Sproat, V. Patel, London, UK

\section{References}

1. Grossman S, Sandhu P, Sproat C, Patel V. Provision of dental services at a single institution in the UK's epicentre during the COVID-19 pandemic. Br Dent J 2020; 228: 964-970.

2. Public Health England, 2020. National COVID-19 Surveillance Report: 11 September 2020 (Week 37). [ebook] Available at: https://assets.publishing. service.gov.uk/government/uploads/system/uploads/ attachment_data/file/916993/Weekly_COVID19_ Surveillance_Report_week_37_FINAL.pdf (accessed 17 September 2020)

https://doi.org/10.1038/s41415-020-2296-x

\section{Why PAPR suits us}

Sir, the move to a total airborne pathogen respiratory risk reduction in dentistry and the added burden of significant PPE changing and disinfection between patients is here for the foreseeable future.

Our options were essentially FFP3 masks or respirators. Tight fitting and designed for limited wear times, these FFP3/non powered respirators are not wholly suited to continuous wear and whilst FFP3 can be comfortable for some colleagues, others have cited varying difficulties with fogging, time taken to don and doff and exorbitant replacement costs. FFP3 therefore seemed a limited option which did not make economic sense. Let us not even consider the term 'fit testing. What a chore that was.

The closefitting respirators offered a solution to the cost, but once again were limited for loupe wearers as the nose area creates a vertical raising of the loupes and surgeons are having to strain to focus comfortably with the resultant headaches that eye strain causes. What about the heat generated? We are essentially wearing plastic bags and the mask/visor combination meant that after waiting five minutes for fogging and focusing to start, I was then plagued with condensation forming on my glasses/ loupes! In addition to this, the patient can't see my face at any stage and communication is a chore.

That was fine for four patients a day hobby horsing dentistry, but we needed to get our team back to work, furlough is ending soon and we decided it would be better to consider powered respirators (PAPR). The consideration is that a comfortable dental professional is more likely to be efficient and to enjoy their work. We were determined to buy once and buy right. It takes seconds to put on and take off, most loupes fit in them (please check as not all do), and there is a lovely flow of air across your face, mitigating well against the heat of the aprons.

It's been six weeks since I've been wearing my Centurion Concept Air PAPR and I can say unequivocally we were right to get them. We can perform treatment after treatment without fatigue, you get used to them so much so that I wear it for every patient, even non-AGP, and it is quicker than mask and visor waiting to defog. I am also really appreciating the lack of any scent in the environment. I don't miss the smell of bond or infectious teeth.

Those with a heavy NHS practice commitment might not even be back to any credible workload yet. I know many of us are soldiering on and if you are comfortable with your solutions then fine but if you are tired, irritated and not looking forward to going back to work then change your direction and consider PAPR.

H. Mostafa, Leamington Spa, UK https://doi.org/10.1038/s41415-020-2297-9 